\title{
Dentinogenesis imperfecta
}

\author{
INSERM
}

\section{Source}

INSERM. (1999). Orphanet: an online rare disease and orphan drug data base.

Dentinogenesis imperfecta. ORPHA:49042

Dentinogenesis imperfecta (DGI) is a hereditary dentin defect (see this term)

characterized by abnormal dentin structure resulting in abnormal tooth development. 